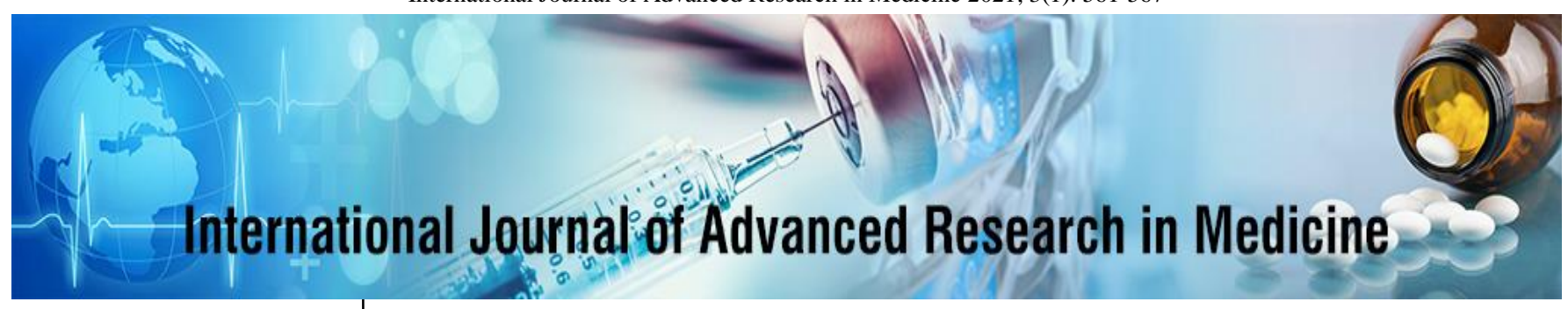

E-ISSN: 2706-9575

P-ISSN: 2706-9567

IJARM 2021; 3(1): 561-567

Received: 06-06-2021

Accepted: 27-06-2021

Dr. Reyya Mohan Sundar MD. Assistant Professor, Department of Physiology, TRR Institute of Medical Sciences, TRR Nagar, Inole, Patancheru, Sangareddy, Telangana, India
Corresponding Author: Dr. Reyya Mohan Sundar MD., Assistant Professor, Department of Physiology, TRR Institute of Medical Sciences, TRR Nagar, Inole, Patancheru, Sangareddy, Telangana, India

\section{A comparative study of blood indices in rural and urban non-pregnant female population of East Godavari district, Andhra Pradesh}

\author{
Dr. Reyya Mohan Sundar
}

DOI: https://doi.org/10.22271/27069567.2021.v3.i1i.316

\begin{abstract}
Background: Anemia is still a major health problem in females of both rural and urban areas of the developing countries like India. The objective of the present study was to find out the hematological parameters and blood indices among non - pregnant females in rural and urban areas of East Godavari District, Andhra Pradesh, India and correlate to type of anemia, degree of anemia, and percentage of anemia in both the rural as well as urban areas non-pregnant female subjects.

Methods: A cross-sectional study was conducted among non-pregnant female subjects of age group 18 -35 years comprised of $n=100$ subjects selected from rural area and $n=100$ subjects from urban areas of East Godavari District, Andhra Pradesh, India. The haematological parameters, $\mathrm{Hb}$ gm\%, $\mathrm{MCV}$ (fL), RBC count / $\mathrm{mm}^{3}, \mathrm{MCH}(\mathrm{pg}), \mathrm{PCV}(\%), \mathrm{MCHC}(\mathrm{gm} / \mathrm{dL}$ ) were investigated by Haematology Analyser - automated blood cell counter.

Results: among the total sample of $\mathrm{n}=200$ non-pregnant female subjects of age group 18-45 years, the overall prevalence of anemia was observed 58\%, recording $60 \%$ in rural area females and $56 \%$ in nonpregnant female subjects of urban area. The overall microcytic anemia was observed maximum (40\%), recording $70 \%$ in rural area subjects and $67 \%$ in urban area subjects. The overall macrocytic anemias and normocytic aneamias were recorded $9 \%$ each. The macrocytic anemias were recorded $13.5 \%$ in the rural area and $17.8 \%$ in urban area. The normocytic anemias recorded $16.6 \%$ in rural area and $14.2 \%$ in urban area non-pregnant female subjects. Anova test done between non-anemic and anemic microcytic, macrocytic and normocytic groups, t-test done between every two parameters were statistically significant at $p \leq 0.005$.

Conclusion: The present study results indicates the prevalence of anemia is slightly higher among rural non-pregnant female subjects of age group 18 - 35 years compared to urban area female subjects considering it to be a major health problem in the females of both rural as well as urban areas of developing countries like India. The current study results suggests, need of due emphasis on iron and folic acid supplementation and health and education on the consumption of iron rich foods, so as to bring down the prevalence of anemia among the adolescent girls.
\end{abstract}

Keywords: Anemia, blood indices, non-pregnant females

\section{Introduction}

Anemia appeared as a serious public health problem throughout the world, particularly in developing countries ${ }^{[1,2]}$. WHO estimates the number of anemic people worldwide to be a staggering two billion i.e. $27 \%$ of the world's population had anemia in $2019^{\text {[3] }}$. It is also estimated that one third of all women of reproductive age are anemic ${ }^{[4]}$. The World Health Organization (WHO) reported that $58 \%$ of the pregnant women with anemia were also anemic before being pregnant ${ }^{[5]}$. Prevention of anemia in non-pregnant women could improve the health status of the pregnant women, eventually contributing to the reduction of both maternal and perinatal mortality.

India is said to account for approximately a quarter of all cases of anemia globally. In India, nationally representative data from the National Family Health Survey 1998-1999 (International Institute of Population Sciences and ORC Macro 2000) on anemia of women of reproductive age describe the magnitude of the problem. The prevalence of anemia among all women in the Indian sample is $52 \%$.

Anemia or Anaemia (hereby referred as Anemia) is characterized as decreased quantity of red blood cells in body, which is accompanied by diminished haemoglobin levels or altered red blood cell morphology ${ }^{[2]}$. 
It is estimated that anemia affects $29 \%$ (496 million) of nonpregnant women, $38 \%$ (32.4 million) of pregnant women aged 15 - 49 years and $43 \%$ of children worldwide ${ }^{[6,7]}$. According to the World Health Organization (WHO), an anemic condition may be termed severe, mild or moderate, depending on the $\mathrm{Hb}$ status of the individual.

Maxwell Wintrobe ${ }^{[8]}$ worked out Blood indices and applied them to the classification of anemias. Red cell indices are valuable in the morphologic classification of anemias. Blood indices include, MCV, (mean corpuscular volume), $\mathrm{MCH}$, (mean corpuscular haemoglobin), MCHC (mean corpuscular haemoglobin concentration).

Based on these Blood Indices, anemias are categorized into microcytic anemia, macrocytic anemia, normocytic anemia and hypochromic and normochromic type. Anemia of any type affects tests such as $\mathrm{Hb}$ valus, $\mathrm{RBC}$ count, haematocrit (Hct). The haemoglobin test is a measure of haemoglobin (a protein in red blood cells) concentration of blood. Haematocrit is a measurement of the amount of red blood cells or space occupied by red blood cell in the blood. Both hemoglobin and hematocrit are used to diagnose anemia.

The values of $\mathrm{Hct}, \mathrm{Hb}, \mathrm{RBC}$, are converted into blood indices viz., $\mathrm{MCV}, \mathrm{MCH}, \mathrm{MCHC}$, through mathematical formulas and these blood indices categories the anemias into microcytic (decreased MCV), macrocytic (increased MCV), normocytic (normal MCV) and hypochromic and normochromic types.

Anemias are major health problem in females of reproductive age women, in developing and developed countries of the world. In India, more than $50 \%$ of all the females are suffering from anemia both in rural as well as urban areas. The most common type by which females of reproductive age women are suffering are "Iron deficiency anemia, vitamin B12 and folic acid deficiency anemias, anemias due to blood loss and haemolytic anemias. These anemias are categorized as microcytic anemias, macrocytic anemias, and normocytic anemias. Microcytic anemia is iron deficiency anemia, commonly occurring in females of reproductive age women in India. Macrocytic anemias are Vitamin B12 or folic acid deficiency anemias, also occurring in females of reproductive age group. Normocytic anemias occurring in females are due to blood loss or hemolytic anemias. In India more than $50 \%$ females of reproductive age women are suffering from iron deficiency anemia which is a type of microcytic anemia. Iron deficiency anemias are majorly due to dietary deficiency, Hookworm infestations, menstruation blood loss, depletion of iron stores due to increased physiological demands in reproductive age, pregnancy, multiparity, reduced space between pregnancies, postpartum haemorrhage, breast feeding. Iron deficiency anemia is the common type occurring in both rural and urban females of reproductive age women, but more commonly occurring in rural females than urban. This is correlated to lack of education, low economical status, poor nutrition, poor hygiene, hookworm infestations, early marriage, multi parity, reduced spacing between pregnancy and lack of health infrastructure. Examples of macrocytic anemias are vitamin B12 deficiency anemias observed in vegetarians and folic acid deficiency observed in those taking vegetarian food, which is observed in elderly than younger females. The other types are normocytic anemias due to blood loss, acute or chronic and some due to hemolytic anemias. There are two main ways to classify the anemias: a. Morphologically (based on red cell size and haemoglobin content)

1) Microcytic hypochromic

2) Macrocytic

3) Normocytic normochromic

b. Pathophysiological (based on causative factors)

1) Blood Loss

2) Impaired $\mathrm{RBC}$ production

3) Increased RBC destruction

The type of anemia occurring in rural and urban females is categorized by these blood indices (MCV, MCH, MCHC). MCV measures the average volume of red blood cell and is the indicator of $\mathrm{RBC}$ size and discriminate between microcytic or macrocytic anemias. Microcytic anemias have small RBCs and decreased MCV. Microcytic anemias reflected low MCV due to defective $\mathrm{Hb}$ production either from ineffective haeme or globin synthesis. Microcytic anemia examples are iron deficiency anemia, anemia of chronic illness, beta thalassemia. Iron deficiency anemia the most common type of microcytic anemia. Macrocytic anemia occurs with nutritional deficiency examples are vitamin B12 and folic acid deficiency. Normocytic anemia with normal MCV and normal sized RBC's occurring in acute blood loss or hemolytic anemia. $\mathrm{MCH}$ is the average weight of $\mathrm{Hb}$ in red blood cell. MCHC measure the average concentration of $\mathrm{Hb}$ in a red blood cell. Cells with normal concentration of $\mathrm{Hb}$ are called normochromic. Cells with decreased concentration of $\mathrm{Hb}$ are hypochromic. Anemias are categorized as hypochromic or normochromic according to MCHC index. So the comparative study of blood indices categorises the type of anemia in females. Decreased MCV, $\mathrm{MCH}$ and $\mathrm{MCHC}$ values discriminate them into microcytic, hypochromic anemias. Increased MCV and normal MCHC and $\mathrm{MCH}$ discriminate them into macrocytic anemia. Normal $\mathrm{MCV}, \mathrm{MCHC}$ and $\mathrm{MCH}$ values are seen in normocytic normochromic anemia. The purpose of the comparative study of blood indices is to derive $\mathrm{MCV}, \mathrm{MCH}$, MCHC from haematological parameters $\mathrm{Hb}$, total $\mathrm{RBC}$ count, PCV or hematocrit, from a sample population including females of reproductive age group (18 - 35 years) in both rural and urban areas. Statistical analysis was done and the prevalence of anemia and types of anemias areawise and age-wise noted and compared in both rural and urban non-pregnant females which will help further in preventive, differentiating and diagnostic aspects of anemia in non-pregnant females of rural and urban areas of East Godavari District, Andhra Pradesh, India.

Most of the previous studies were focused on the prevalence and determinants of anemia among pregnant women ${ }^{[4,9,10]}$. However, there are a few studies assessing the prevalence of severe anemia among non-pregnant women.

In view of the above, the present study was carried out to find out the prevalence of anemia in non-pregnant female population of rural and urban areas of East Godavari District, Andhra Pradesh, India.

The present study was aimed to find out the haematological parameters such as $\mathrm{Hb}$ (gm\%), Total RBC (count / mm3), and packed cell volume (PCV in \%) among non-pregnant females of age group (18 - 35 years) in rural and urban areas of East Godavari Dist, Andhra Pradesh, India. To derive blood indices: MCV (fL), MCH (pg), MCHC (g/dL). The blood indices study helps anemia detection and typing of 
anemias. Hence, these blood indices of non-pregnant females of age group ( 18 - 35 years) were compared among rural and urban areas of East Godavari district.

\section{Material and Methods}

The study sample population and sample size included nonpregnant females of age group 18 - 35 years constituting $n=$ 100 subjects (cases) in rural area and $n=100$ subjects in urban area.

\section{The study population included}

- The subjects in the field practicing areas of UHC (Urban Health Center) and RHC (Rural Health Center) under GSL Medical College and General Hospital, Rajahmundry.

- The rural and urban areas of East Godavari District viz., Rajahmundry, Rajanagaram and Kakinada.

Haematological parameters and blood indices were done and calculated at (a) Central Lab of GSL Medical College and Hospital, Rajahmundry (b) Rajanagaram PHC and Lab. (Pvt.) (c) Kakinada (Pvt. Maternity Hospital and Lab).

Inclusion criteria included normal adult females of age group between 18 - 35 years.

Exclusion criteria included pregnant women, elderly women, children, females suffering from haematological disorders, leukemia, myeloproliferative disorders.

The study design was cross sectional study using simple random sampling, appropriate sample size was taken. The study was conducted for a period of one year.

Study variables included: age, gender, marital status, education, family back ground, nutrition, income.

Permission from Head of the Department was taken. The approval from the Ethical committee of the institution was taken. All the study subjects were informed about this study protocol and written consent was obtained from the subjects prior to the procedure.

\section{Procedure}

A sterile $5 \mathrm{ml}$ syringe was taken for collection of blood sample following strict aseptic measures. Venous blood samples were collected into anti-coagulant (EDTA) added sample tubes.

The haematological parameters such as hemoglobin (gm \%), Total RBC Count / mm3, PCV (\%) were investigated. Blood Indices like MCV (fL), $\mathrm{MCH}$ (pg) and MCHC (g / dL) were calculated.

All the above haematological parameters were analyzed by Hematology analyser- automated blood cell counter (SYSMEX XP-100) in the central Lab of GSL Medical College General Hospital.

Following normal ranges for haematological parameters and blood indices were followed:

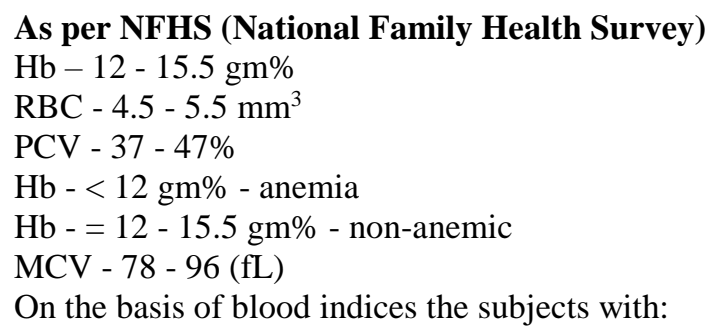

MCV - $<78 \mathrm{fL}$ (considered as microcytic anemia)

MCV - > $96 \mathrm{fL}$ (macrocytic anemia)

MCV - $<78$ - $96 \mathrm{fL}$ (normocytic anemia)

$\mathrm{MCH}-27$ - 33 (pg)

MCHC - 30 - 37\% (normochromic anemia)

MCHC - <30\% (hypochromic anemia)

\section{Statistical analysis}

The statistical analysis data is correlated to distribution and percentage of anemia, degree of anemia, types of anemia in both rural and urban areas compared, which helps in preventive, differentiating and diagnostic aspects of anemia. The statistical analysis was done by using SPSS software version-20 and MS excel- 2007.

All descriptive statistical values were presented in the form of mean \pm standard deviations and percentages.

Student-t test and ANOVA Test was performed to compare the means of different groups, correlation was performed to assess the relation among the various variables

ANOVA Test was done between non-anemic and anemic females and microcytic, macrocytic, normocytic groups. Student-t Test was done between every two parameters. The statistical analysis $p$ value $\leq 0.05$ was considered as statistically significant.

\section{Results}

The statistical analysis data of comparison of haematological parameters and blood indices in nonpregnant females of age group between 18 - 35 years and between anemic and non-anemic in rural areas is presented in the Table 1. The statistical analysis data in the Table shows that there is a highly significant $(P<0.01)$ difference in all parameters studied except for RBC in non-pregnant females of age group between $18-35$ years.

Table 1: Comparison of haematological parameters and blood indices in non-pregnant females subjects of age group (18 - $35 \mathrm{yrs})$ between anemic and non-anemic in rural area

\begin{tabular}{|c|c|c|c|c|c|c|}
\hline Par & Group & $\mathbf{n}$ & Mean & SD & $p$ & INI \\
\hline \multirow{2}{*}{$\mathrm{Hb}(\mathrm{gm} \%$} & Anemic & 60 & 9.97 & 0.997 & \multirow{2}{*}{0.000} & \\
\hline & Non anem & 40 & 12.56 & 0.396 & & \\
\hline \multirow{2}{*}{\begin{tabular}{|c|}
$\mathrm{RBC}$ \\
(millions / mm3) \\
\end{tabular}} & & 30 & 4.390 & .3745 & \multirow{2}{*}{0.793} & \\
\hline & Non a & 20 & 4.415 & .2412 & & \\
\hline \multirow{2}{*}{$\operatorname{PCV}(\%)$} & $\mathrm{An}$ & 30 & 4.507 & 3.4495 & & \\
\hline & Non & 20 & 0 & 2.0201 & & \\
\hline \multirow{2}{*}{$\mathrm{MCV}$} & $\mathrm{An}$ & 30 & 78.500 & 11.5021 & & \\
\hline & Non : & 20 & 91.085 & 3.8429 & & \\
\hline \multirow[b]{2}{*}{ ) } & $\mathrm{An}$ & 30 & 22.667 & 3.5706 & & \multirow[b]{2}{*}{$\mathrm{H}$} \\
\hline & Non & 2 & 28 & 1.4357 & & \\
\hline \multirow{2}{*}{$\mathrm{MCHC}$} & & 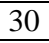 & & 2.4319 & \multirow[b]{2}{*}{0.00} & \multirow[b]{2}{*}{$\mathrm{H}$} \\
\hline & Non anem & 20 & 31.340 & 2.0184 & & \\
\hline
\end{tabular}

\section{SD- Standard Deviation; HS- highly significant}

The statistical analysis data of comparison of haematological parameters and blood indices in nonpregnant female subjects of age group 18 - 35 years between anemic and non-anemic in urban area is given in the Table 2. The statistical analysis data in the table shows that there is a highly significant $(P<0.01)$ difference in all the parameters studied except for the RBC count in nonpregnant female subjects of age group 18 - 35 years. 
Table 2: Comparison of haematological parameters and blood indices in non-pregnant female subjects of age group (18 - 35 yrs) between anemic and non-anemic in urban area

\begin{tabular}{|c|c|c|c|c|c|c|}
\hline Parameters & Group & $\mathbf{n}$ & Mean & Std. Deviation & $p$ Value & INF \\
\hline \multirow{2}{*}{$\mathrm{Hb}(\mathrm{gm} \%)$} & Anemic & 56 & 10.15 & .532 & \multirow{2}{*}{0.000} & \multirow{2}{*}{ HS } \\
\hline & Non anemic & 44 & 12.56 & .645 & & \\
\hline \multirow{2}{*}{ RBC (millions / mm3) } & Anemic & 28 & 7.379 & 10.6352 & \multirow[t]{2}{*}{0.185} & \multirow[t]{2}{*}{ NS } \\
\hline & Non anemic & 22 & 4.318 & .3002 & & \\
\hline \multirow{2}{*}{ PCV $(\%)$} & Anemic & 28 & 35.696 & 3.0789 & \multirow{2}{*}{0.000} & \multirow{2}{*}{ HS } \\
\hline & Non anemic & 22 & 38.932 & 2.4396 & & \\
\hline \multirow{2}{*}{ MCV (fL) } & Anemic & 28 & 79.568 & 12.2190 & \multirow{2}{*}{0.001} & \multirow{2}{*}{ HS } \\
\hline & Non anemic & 22 & 89.609 & 3.7369 & & \\
\hline \multirow{2}{*}{$\mathrm{MCH}(\mathrm{pg})$} & Anemic & 28 & 22.529 & 3.3554 & \multirow{2}{*}{0.000} & \multirow{2}{*}{ HS } \\
\hline & Non anemic & 22 & 28.882 & 1.6112 & & \\
\hline \multirow{2}{*}{$\mathrm{MCHC} \mathrm{g} / \mathrm{dL}$} & Anemic & 28 & 28.971 & 2.3442 & \multirow{2}{*}{0.000} & \multirow{2}{*}{ HS } \\
\hline & Non anemic & 22 & 32.505 & 1.8123 & & \\
\hline
\end{tabular}

Table 3: Comparison of the parameters between microcytic, macrocytic, normocytic anemias and non-anemic among non-pregnant female subjects in rural area

\begin{tabular}{|c|c|c|c|c|c|c|c|c|c|c|c|c|c|}
\hline \multicolumn{2}{|c|}{ Dependent Variable } & Hb gm\% & \multicolumn{2}{c|}{ RBC count / mm3 } & \multicolumn{2}{c|}{ PCV\% } & \multicolumn{2}{c|}{ MCV (fL) } & \multicolumn{2}{|c|}{ MCH (pg) } & \multicolumn{2}{c|}{ MCHC g / dL } \\
\hline (I) GRP & (J) GRP & P-Val & Inf & P-Val & Inf & P-Val & Inf & P-Val & Inf & P-Val & Inf & P-Val & Inf \\
\hline Macrocytic & Microcytic & 0.001 & HS & 0.016 & NS & 0.000 & HS & 0.000 & HS & 0.000 & HS & 0.010 & NS \\
\hline Macrocytic & Normocytic & 0.235 & NS & 0.666 & NS & 0.000 & HS & 0.000 & HS & 0.012 & NS & 0.000 & HS \\
\hline Macrocytic & Non anemic & 0.000 & HS & 0.076 & NS & 0.812 & NS & 0.000 & HS & 0.013 & NS & 0.000 & HS \\
\hline Macrocytic & Microcytic & 0.000 & HS & 0.016 & NS & 0.000 & HS & 0.000 & HS & 0.000 & HS & 0.010 & NS \\
\hline Macrocytic & Normocytic & 0.000 & HS & 0.002 & HS & 0.568 & NS & 0.000 & HS & 0.000 & HS & 0.000 & HS \\
\hline Macrocytic & Non anemic & 0.000 & HS & 0.238 & HS & 0.000 & HS & 0.000 & HS & 0.000 & HS & 0.000 & HS \\
\hline Macrocytic & Microcytic & 0.235 & NS & 0.666 & NS & 0.000 & HS & 0.000 & HS & 0.012 & NS & 0.000 & HS \\
\hline Macrocytic & Microcytic & 0.000 & HS & 0.002 & NS & 0.568 & NS & 0.000 & HS & 0.000 & HS & 0.000 & HS \\
\hline Macrocytic & Non anemic & 0.000 & HS & 0.013 & HS & 0.000 & HS & 0.008 & NS & 0.497 & NS & 0.044 & NS \\
\hline Non anemic & Microcytic & 0.000 & HS & 0.076 & NS & 0.812 & NS & 0.000 & HS & 0.013 & NS & 0.000 & HS \\
\hline Non anemic & Normocytic & 0.000 & HS & 0.238 & NS & 0.000 & HS & 0.000 & HS & 0.000 & HS & 0.000 & HS \\
\hline Non anemic & Microcytic & 0.000 & HS & 0.013 & NS & 0.000 & HS & 0.008 & NS & 0.497 & NS & 0.044 & NS \\
\hline
\end{tabular}

Table 4: Comparison of the parameters between microcytic, macrocytic, normocytic anemias and non-anemic among non-pregnant female subjects in urban area

\begin{tabular}{|c|c|c|c|c|c|c|c|c|c|c|c|c|c|}
\hline \multicolumn{2}{|c|}{ Dependent Variable } & \multicolumn{2}{|c|}{ Hb gm\% } & \multicolumn{2}{c|}{ RBC count / mm3 } & \multicolumn{2}{|c|}{ PCV\% } & \multicolumn{2}{c|}{ MCV (fL) } & \multicolumn{2}{|c|}{ MCH (pg) } & \multicolumn{2}{c|}{ MCHC g/ dL } \\
\hline (I) GRP & (J) GRP & P-Val & Inf & P-Val & Inf & P-Val & Inf & P-Val & Inf & P-Val & Inf & P-Val & Inf \\
\hline Macrocytic & Microcytic & 0.000 & HS & 0.016 & NS & 0.000 & HS & 0.000 & HS & 0.000 & HS & 0.705 & NS \\
\hline Macrocytic & Normocytic & 0.876 & NS & 0.666 & NS & 0.000 & HS & 0.000 & HS & 0.731 & NS & 0.060 & NS \\
\hline Macrocytic & Non anemic & 0.000 & HS & 0.076 & NS & 0.812 & NS & 0.000 & HS & 0.018 & NS & 0.001 & HS \\
\hline Macrocytic & Macrocytic & 0.000 & HS & 0.016 & NS & 0.000 & HS & 0.000 & HS & 0.000 & HS & 0.705 & NS \\
\hline Macrocytic & Normocytic & 0.000 & HS & 0.002 & HS & 0.568 & NS & 0.000 & HS & 0.000 & HS & 0.010 & NS \\
\hline Macrocytic & Non anemic & 0.000 & HS & 0.238 & HS & 0.000 & HS & 0.000 & HS & 0.000 & HS & 0.000 & NS \\
\hline Normocytic & Macrocytic & 0.586 & NS & 0.666 & NS & 0.000 & HS & 0.000 & HS & 0.731 & NS & 0.060 & NS \\
\hline Normocytic & Microcytic & 0.000 & HS & 0.002 & NS & 0.568 & NS & 0.000 & HS & 0.000 & HS & 0.010 & NS \\
\hline Normocytic & Non anemic & 0.000 & HS & 0.013 & HS & 0.000 & HS & 0.011 & NS & 0.011 & NS & 0.353 & NS \\
\hline Non aneamic & Macrocytic & 0.000 & HS & 0.076 & NS & 0.812 & NS & 0.000 & HS & 0.018 & NS & 0.001 & HS \\
\hline Non aneamic & Normocytic & 0.000 & HS & 0.238 & NS & 0.000 & HS & 0.000 & HS & 0.000 & HS & 0.000 & HS \\
\hline Non aneamic & Microcytic & 0.000 & HS & 0.013 & NS & 0.000 & HS & 0.011 & NS & 0.011 & NS & 0.353 & NS \\
\hline
\end{tabular}

The data of Anova analysis of all the parameters studied in non-pregnant subjects among rural and urban areas is represented in the Table 5. The Anova analysis data of all parameters studied shows that the $p$-values are highly significant $(p<0.005)$ for all hematological parameters and blood indices in female subjects of both rural as well as urban areas, except for RBC counts, where $p$-value is > 0.005 which is not statistically significant. This implies that the data of the parameters studied shows that the anemia prevails in the selected subjects of both rural as well as urban areas. The statistical analysis data of $p$-values showed statistically significant correlation with blood indices MCV, $\mathrm{MCH}, \mathrm{MCHC}$, indicating the presence of microcytic, macrocytic and normocytic anemias.
Table 5: ANOVA analysis data showing $p$ values of all the parameters studied among non-pregnant female subjects of rural and urban areas

\begin{tabular}{|c|c|c|c|c|}
\hline \multirow{2}{*}{ Parameters } & \multicolumn{2}{|c|}{ Rural } & \multicolumn{2}{|c|}{ Urban } \\
\cline { 2 - 5 } & $\boldsymbol{p}$ value & INF. & $\begin{array}{c}\boldsymbol{p} \\
\text { value }\end{array}$ & INF. \\
\hline Hb (gm \%) & 0.000 & $P<0.005(\mathrm{HS})$ & 0.000 & $P<0.005(\mathrm{HS})$ \\
\hline RBC(millions / mm3) & 0.004 & $P<0.005(\mathrm{HS})$ & 0.027 & $P<0.005(\mathrm{NS})$ \\
\hline $\mathrm{PCV}(\%)$ & 0.000 & $P<0.005(\mathrm{HS})$ & 0.000 & $P<0.005(\mathrm{HS})$ \\
\hline MCV (fL) & 0.000 & $P<0.005(\mathrm{HS})$ & 0.000 & $P<0.005(\mathrm{HS})$ \\
\hline MCH (pg) & 0.000 & $P<0.005(\mathrm{HS})$ & 0.000 & $P<0.005(\mathrm{HS})$ \\
\hline
\end{tabular}

The percentage distribution of anemia in female nonpregnant subjects of rural and urban areas is presented in Table 6. The data shows that in a total sample of $n=200$ 
subject females (18 - $35 \mathrm{yrs})$, the overall prevalence of anemia is $58 \%$, in rural females the anemia prevalence is $60 \%$, while in urban females it is $56 \%$. Among the total $\mathrm{n}=$ 200 subjects, the microcytic anemia was observed to be maximum in prevalence recording $40 \%$, the microcytic anemia in the females of rural area was observed $70 \%$ and in urban females $67.8 \%$. Out of the total $n=200$ subjects the overall macrocytic and normocytic anemia recorded were $9 \%$ each. In the female subjects of the rural area the macrocytic anemia was $13.5 \%$ and in urban area $17.8 \%$ and the normocytic anemia in the rural area was recorded $16.6 \%$ while in urban area $14.2 \%$.

Table 6: Percentage distribution of anemia among non-pregnant female subjects in rural and urban areas

\begin{tabular}{|c|c|c|c|}
\hline Types of anemia & Rural (n=100) & Urban $(\mathbf{n}=\mathbf{1 0 0})$ & Total $(\mathbf{n = 2 0 0})$ \\
\hline Anemia (\%) & 60 & 56 & 58 \\
\hline Microcytic anemia & 70 & 67.8 & 40 \\
\hline Macrocytic anemia & 13.5 & 17.8 & 9 \\
\hline Normocytic anemia & 16.6 & 14.2 & 9 \\
\hline Non anemic & 40 & 44 & 42 \\
\hline
\end{tabular}

The results of comparison of haematological parameters and blood indices in non-pregnant female subjects of anemic and non-anemic in rural and urban areas are shown in the Fig. 1. The data recorded showed that there is a high statistically significant $(P<0.001)$ difference in the parameters such as Hb levels, Hct, MCV, MCH and MCHC values between anemic and non-anemic female subjects of the rural area. There is a low significant ( $P>0.001$ ) difference in RBC counts between anemic and non-anemic female subjects of the rural area. There is a high statistically significant $(P<0.001)$ difference in $\mathrm{Hb}$ levels, Hct, MCV, $\mathrm{MCH}$ and $\mathrm{MCHC}$ values between anemic and non-anemic female subjects of the urban area. However, there is no significant $(\mathrm{P}>0.001)$ difference observed in $\mathrm{RBC}$ counts between anemic and non-anemic females of the urban area.

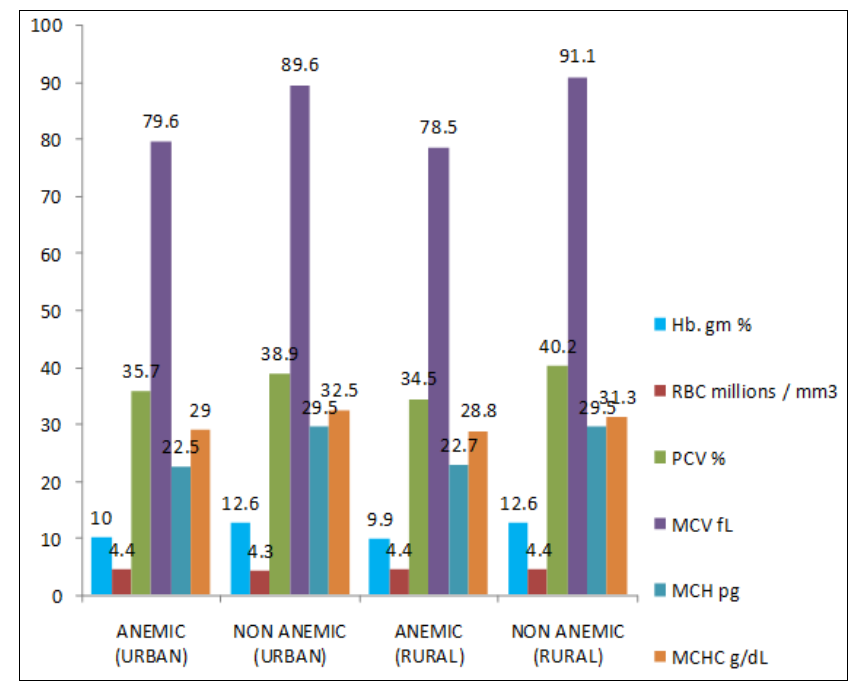

Fig 1: Comparison of haematological parameters and blood indices in non-pregnant female subjects of anemic and non-anemic in rural and urban areas

The data of comparisons of the parameters studied between microcytic, macrocytic, normocytic anemic and non-anemic non-pregnant female subjects of the urban areas presented in the Fig. 2a shows that there is high statistically significant $(p<0.001)$ difference seen among fib, PCV, MCV, MCH values compared to microcytic and macrocytic groups in females of the urban area. There is high statistically significant $(p<0.001)$ difference observed among MCV, $\mathrm{MCH}$ values compared to microcytic and normocytic groups in the females of urban area. There is a high statistically significant $(p<0.001)$ difference observed among $\mathrm{Hb}, \mathrm{PCV}$ values compared to microcytic and non-anemic groups in female subjects of the urban area. There is highly significant ( $p<0.001)$ difference seen among Hb, MCV values compared to macrocytic and narmocytic groups in female subjects of the urban area. There is a highly significant ( $p<$ 0.001 ) difference observed among $\mathrm{Hb}, \mathrm{MCV}, \mathrm{MCH}$ values compared to macrocytic and non-anemic groups in females of urban area. There is a high statistically significant ( $p<$ 0.001) difference observed among PCV, MCV, MCH, MCHC values compared to normocytic and non-anemic groups in females of the urban area.

The statistical analysis data shows that there is statistically highly significant $(p<0.001)$ difference recorded in all the parameters studied except RBC count between anemic and non-anemic non-pregnant females of the urban area.

The statistical analysis data of the comparisons of parameters studied between microcytic, macrocytic, normocytic anemic and non-anemic non-pregnant females of the rural area is presented in Fig. 2b. The statistical analysis data showed that there is statistically highly significant $(p<0.001)$ difference observed in all the parameters studied except RBC counts between anemic and non-anemic non-pregnant females of rural area.

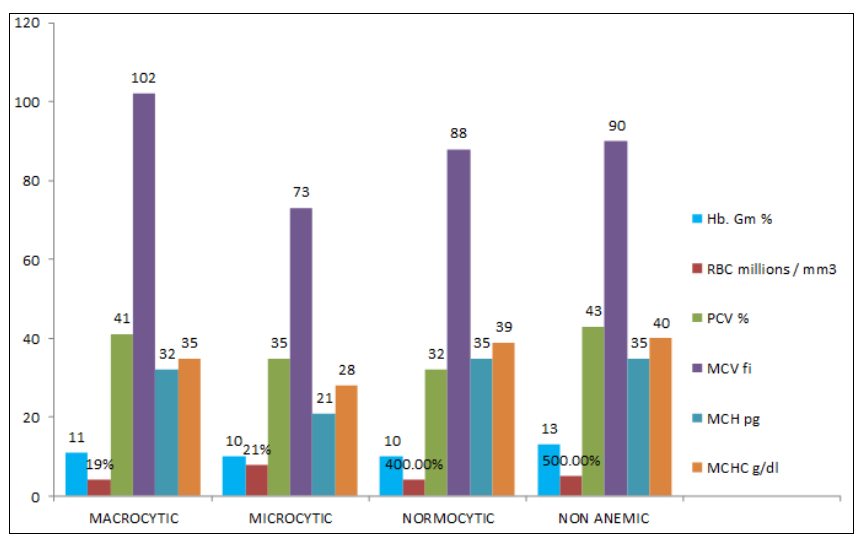

Fig 2a: Comparison of parameters between microcytic, macrocytic, normocytic anemic and non-anemic female subjects of the urban area

The data shows that there is highly significant $(p<0.001)$ difference observed among $\mathrm{Hb}, \mathrm{PCV}, \mathrm{MCV}, \mathrm{MCH}$ values compared to microcytic and macrocytic groups, and among $\mathrm{Hb}, \mathrm{PCV}, \mathrm{RBC}, \mathrm{MCV}, \mathrm{MCH}, \mathrm{MCHC}$ values compared to microcytic and normocytic groups in females of the rural area.

Similarly there is highly significant $(p<0.001)$ difference noted in $\mathrm{Hb}, \mathrm{PCV}$ values compared to microcytic and nonanemic groups and among PCV, MCV, MCHC values compared to macrocytic and normocytic groups in female subjects of the rural areas. There is statistically significant ( $p<0.001)$ difference observed among $\mathrm{Hb}, \mathrm{MCV}, \mathrm{MCHC}$ values compared to macrocytic and non-anemic groups and among $\mathrm{Hb}, \mathrm{PCV}, \mathrm{MCV}, \mathrm{MCH}, \mathrm{MCHC}$ values compared to normocytic and non-anemic groups in non-pregnant subjects of the rural area. 


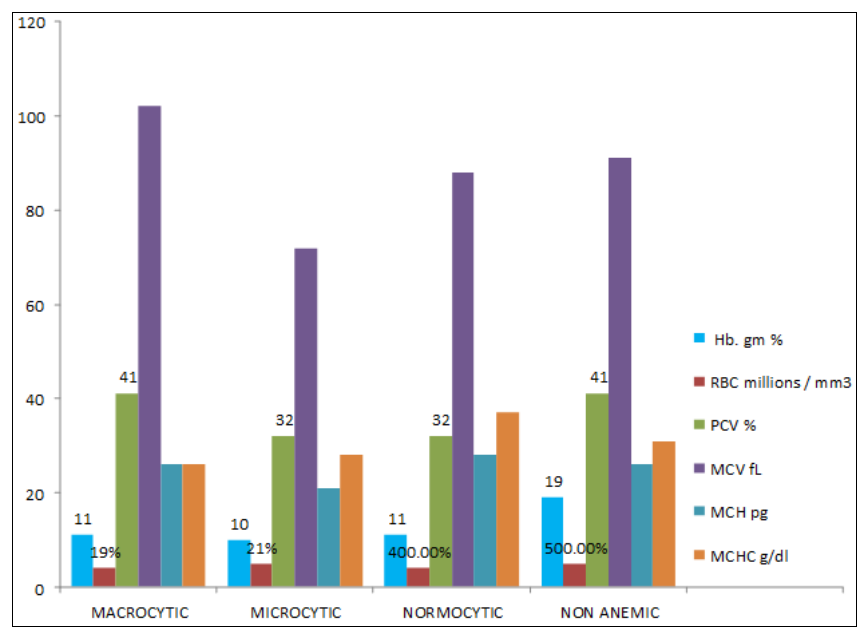

Fig 2b: Comparison of parameters between microcytic, macrocytic, normocytic anemic and non-anemic non-pregnant female subjects of the rural area

The data of distribution of anemia types in rural and urban non-pregnant females shows that microcytic anemia cases are $n=42$ subjects, normocytic anemia subjects are $n=10$, macrocytic anemia $n=8$ in non-pregnant females of rural area while, in rural area microcytic anemia cases are $n=38$, normocytic anemia cases are $\mathrm{n}=8$, macrocytic anemia subjects are $\mathrm{n}=10$.

The data of the distribution of anemic and non-anemic subjects in non-pregnant female subjects of rural and urban area shows that anemic cases are $n=60$ in rural females and $\mathrm{n}=56$ in urban females while, non-anemic cases are $\mathrm{n}=40$ in rural females and $n=44$ in urban female subjects.

The mean age of the urban and rural non-pregnant females is 25.76 and 25.72 respectively which is almost similar in both the areas.

The data of comparison of haematological parameters and blood indices in non-pregnant females of both rural and urban areas is shown in Fig. 3. The data of all parameters studied ( $p>0.005)$ indicates that anemia prevails both in rural and urban non-pregnant females. However, it is slightly higher in females of the rural area compared to urban area females.

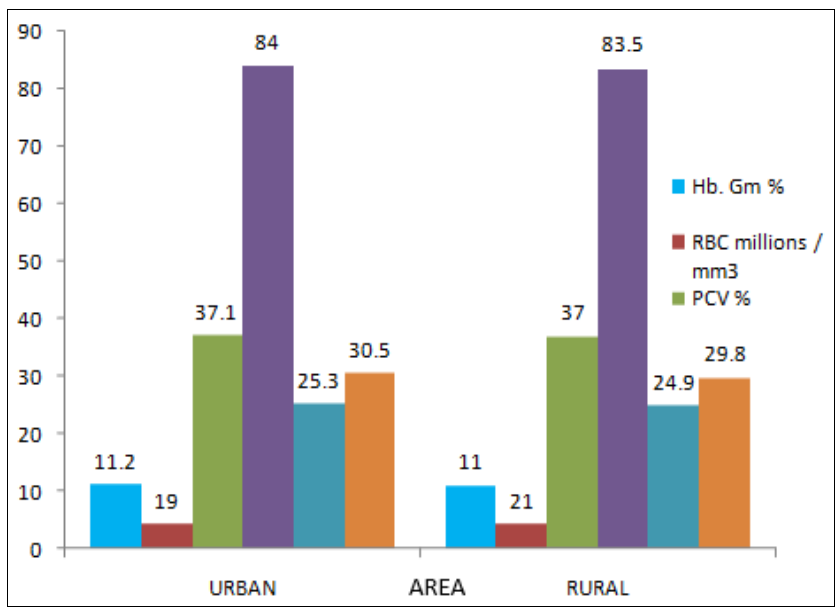

Fig 3: Comparison of haematological parameters and blood indices in non-pregnant female subjects of both rural and urban areas

\section{Discussion}

Over the past few decades most of the anemia related studies were performed on infants, children, adolescents, pregnant women and elderly women. Very few studies were conducted on adult healthy non-pregnant women. In view of this the present study was aimed at detection of anemia and anemia types in the selected non-pregnant females of rural and urban areas of East Godavari district, A.P., India.

In this study the parameters such as $\mathrm{Hb}, \mathrm{RBC}, \mathrm{PCV}$ were taken to determine blood indices viz. MCV, MCH, MCHC and were used to classify anemia. The types of anemias occurring in non-pregnant females of rural and urban areas were categorized based on these blood indices.

A similar study was carried out by Ahmad Hassan et. al [11]. In the present study, for adult healthy female subjects of age group 18 - $35 \mathrm{yrs}$, the normal ranges of $\mathrm{Hb}$ values were 12 $16 \mathrm{~g} / \mathrm{dl}$, RBC 4.0 - 5.5 millions / mm3, PCV 37 - 47\%, for blood indices $\mathrm{MCV}$ were between 78 - $96 \mathrm{fL}, \mathrm{MCH}$ between 27 - 33 pg and MCHC 30 - 37\%. According to WHO (1992) ${ }^{[12]}$ criteria, Hb level $<12 \mathrm{~g} / \mathrm{dL}$ was considered anemia in adult female. On basis of RBC indices anemia with (MCV < $78 \mathrm{fL})$ considered as microcytic anemia, (MCV > $96 \mathrm{fL})$ as macrocytic anemia, (MCV 78-96 fL) as normocytic, MCHC $(30-32 \%)$ as normochromic and MCHC (< 30\%) considered as hypochromic anemia. As per NHFS (National Family Health survey, Hb levels 11.9 - $10 \mathrm{~g} / \mathrm{dl}$ was considered as mild anemia, $9.9-7.0 \mathrm{~g} / \mathrm{dl}$ as moderate and $\mathrm{Hb}<7.0 \mathrm{~g} / \mathrm{dl}$ as severe anemia.

Mcfee ${ }^{[13]}$ studies suggested that at child bearing age women generally suffered from anemia where insufficient diet, multiple pregnancies and excessive hemorrhages are the main causes of anemia. Bentley and Grifths ${ }^{[2]}$ suggested anemia in south Asia as highest in the world. Maninder and Kochar ${ }^{[14]}$ study results reported that rural women have higher prevalence of anemia compared to urban women. Mcfee [13] suggested effects on iron deficiency anemia are protein energy malnutrition (19\%), bleeding from alimentary track (56\%), high bleeding (29\%) during menstruation, pregnancy (6\%). Kapil et al. ${ }^{[15]}$, Saxena et al. ${ }^{[16]}$ reported that $18-30 \%$ women taken diet less than recommended dietry allowance. NFHS (National Family Health Survey) 98 - 99, in A.P. ${ }^{[17]}$ reported that $83 \%$ rural women are married before 18 years. In a study at Eucador, Brazil, Iron deficiency anemia is the most common, followed by normocytic and megalo blastic anemias. Khan et al. ${ }^{[18]}$ study on anemia in rural adult females reported that low level of $\mathrm{Hb}$ may be due to inadequate food consumption, mal-absorbtion, worm infestation or excessive menstrual bleeding. Earlier studies suggested that anemia was more prevalent in rural areas due to lack of health education, inadequate nutrition, improper medication, also observed that macrocytic hypocromic anemia is the most frequent form of anemia followed my macrocytic and other types. Chandra et al. ${ }^{[19]}$ study suggests that B12 deficiency was observed in vegetarian families and infants of breast feeding, as cobalamin content of milk is low in vegetarian mothers. Macrocytic anemia seen in elderly women, ageing process may be the intrinsic factor in development of this type of anemia. Our results indicated that overall prevalence of anemia $(\mathrm{Hb}<12 \mathrm{~g} / \mathrm{dl})$ is $58 \%$. In rural females it is $60 \%$ and in urban females $56 \%$. In urban females anemia is observed to be mild type $(11.9-10 \mathrm{~g} / \mathrm{dl})$ and in rural females mild to moderate type. Overall the commonest type is microcytic anemia, where $\mathrm{MCV}(<78 \mathrm{fL})$ is $40 \%$ and macrocytic anemia (MCV > $96 \mathrm{fL}$ ) and normocytic anemia (MCV 78 - $96 \mathrm{fL}$ ) was $9 \%$ each. The mean age group is 25.7 years. The current study results observed that mean $\mathrm{Hb}$ values were below normal in both rural and urban nonpregnant females. Mean $\mathrm{Hb}$ value was $11 \mathrm{~g} / \mathrm{dl}$ in rural female subjects, and $11.2 \mathrm{~g} / \mathrm{dl}$ in urban females indicating 
that anemia prevails both in rural as well as urban females. Mild type of anemia was observed in urban females, mild to moderate in rural females. The RBC indices such as $\mathrm{MCV}$, $\mathrm{MCH}, \mathrm{MCHC}, p$ value $(p<0.005)$ significantly correlates with microcytic, macrocytic and normocytic anemia. In the present study, occurrence of anemia is slightly higher in rural females compared to urban female subjects. In rural females the most common type of anemia was microcytic, followed by normocytic and finally macrocytic anemia. In urban females the most common type of anemia was microcytic followed by macrocytic and normocytic anemia. The investigations like serum ferritin, iron, TIBC, transferrin saturation, serum B12 or folate levels, electrophoresis are expensive and unavailable to rural area females and also expensive. Rural females usually suffer with chronic infections and inflammatory diseases and the tests available may not correlate significantly with anemia as the tests expensive are unavailable to rural females. Thus, a brief dietary history, family history, local examination with blood indices study helps the clinician greatly in differentiating and diagnostic aspects of the anemia.

In the current study, anemia occurrence slightly higher in rural area females compared to urban area females, in rural females most common types are microcytic anemia followed by normocytic and macrocytic anemia. In urban females the commonest type are microcytic anemia followed by macrocytic and normocytic anemia in female subjects of age group 18 - 35 years among rural and urban areas of East Godavari district, Andhra Pradesh. As per the national guidelines antenatal programs included, however there is a still a need to reinforce this key element and give sufficient importance to it as an intervention for reducing maternal morbidity and mortality. Delaying the first pregnancy in 20 years of age and improvement in prepregnancy nutritional status should be emphasized. Periodical studies will highlight problems related to anemia in females if anemia surveys are conducted in multiple project areas the sample size will be large enough, by combining the data from all the projected areas. The present study warrant a need for attention to anemia among the age group studied and further study on a large population sample and eventually encouraging the development of directed educational and nutritional programs to safe guard the well being of the future mothers.

\section{Conclusion}

The present study results indicates the prevalence of anemia is slightly higher among rural non-pregnant females compared to urban females considering it to be a major health problem in the females of both rural as well as urban areas of developing countries like India. The results showed that in urban females mild type of anemia is common, while in rural mild to moderate type. The current study results suggests, need of due emphasis on iron and folic acid supplementation and health and education on the consumption of iron rich foods, so as to bring down the prevalence of anemia among the adolescent girls. Prevention of anemia in non-pregnant female could improve the health status of the pregnant women and safe guard the wellbeing of the future mothers, eventually contributing to the reduction of both maternal and perinatal mortality.

\section{References}

1. Sharma P, Mehta S, Nagar R. Prevalence of anemia and socio-demographic factors associated with anemia among pregnant women attending antenatal Hospital in Jaipur City, India. IOSR J Pharm. Biol. Sci. 2013;6:1-5.

2. Bentley ME, Griffiths PL. The burden of anemia among women in India. Eur. J Clin. Nutr. 2003;57:52-60.
3. Worldwide prevalence of anaemia: WHO global database on anaemia / Edited by Bruno de Benoist, Erin McLean, Ines Egli and Mary Cogswell. 1993-2005.

4. Kassebaum NJ, Jasrasaria R, Naghavi M, Wulf SK, Johns N, Lozano R, et al. A systematic analysis of global anemia burden from 1990 to 2010. Blood Journal. 2014;123:615-624.

5. World Health Organization (WHO). The Prevalence of Anaemia in Women: A Tabulation of Available Information; World Health Organization: Geneva, Switzerland. 1992.

6. Stevens GA, Finucane M, De-Regil LM, Flaxman SR, Branca F, Peña-Rosas JB, et al. Global, regional, and national trends in haemoglobin concentration and prevalence of total and severe anaemia in children and pregnant and non-pregnant women for 1995-2011: a systematic analysis of population-representative data. Lancet Glob Health. 2013;1:16-25.

7. World Health Organization. Global Nutrition Targets 2025: Anaemia Policy Brief. World Health Organization. 2014.

8. Wintrobe MM. Anemia: classsification and treatment on the basis of differences in the average volume and hemoglobin content of red corpuscles. Arch Intern Med. 1934;54:256

9. Alem M, Enawgaw B, Gelaw A, Kenaw T, Seid M, Olkeba Y. Prevalence of anemia and associated risk factors among pregnant women attending antenatal care in Azezo Health Center Gondar town, Northwest Ethiopia. J Interdiscip. Histopathol. 2013;1:137-144.

10. Gomes da Costa A, Vargas S, Clode N, Graça LM. Prevalence and risk factors for iron deficiency anemia and iron depletion during pregnancy: A prospective study. Acta Med. Port. 2016;29:514-518.

11. Ahmad Hasan Sulthan et al. Anemia among female students at university of Sharjah, UAE, prevalence and classification. J Egypt Public Health Association. 2007;82:3-4.

12. World health organization. The prevalence of anemia in women: atabulation of available information. Geneba: World health organization. 1992.

13. Mcfee JC. Iron metabolism and iron deficiency during pregnancy. Clin. Obstet. Gynocol. 1979;22:799-806.

14. Maninder K, Kochar GK. Burden of Anaemia in Rural and Urban Jat Women in Haryana State, India. Malaysian Journal of Nutrition. 2009;15(2):175-184.

15. Kapil U, Pathak P, Tendon M, Singh C, Pradhan R, Dwivedi SN. Micronutrient deficiency disorders among reproductive women in three urban slum communities of Delhi. Indian paediat. 1999;36(10):983-989.

16. Saxena V, Srivistav VK, Idris MZ, Mohan U, Bharath V. Nutritional status of rural pregnant women. Indian Journal of Corn Med. 2000;3:104-107.

17. National Family Health Survey (NFHS-2), India. 199898 Andhra Pradesh, International Institute for Population. Surinder Kaur, Nutrition Foundation of India. 1989.

18. Khan Z, Nawaz M, Khan A, Bacha U. Hemoglobin, red blood cell count, hematocrit and derived parameters for diagnosing anemia in elderly males. Proceedings of the Pakistan Academy of Sciences. 2013;50(3):217-226.

19. Chandra J. Megaloblastic anemia: back in focus. Indian J Pediatr. 2010;77:795-799. 